\title{
Enhanced Atlantic subpolar gyre variability through baroclinic threshold in a coarse resolution model
}

\author{
M. Mengel ${ }^{1,2}$, A. Levermann ${ }^{1,2}$, C.-F. Schleussner ${ }^{1,2}$, and A. Born ${ }^{3,4}$ \\ ${ }^{1}$ Potsdam Institute for Climate Impact Research, Telegrafenberg A62, 14473 Potsdam, Germany \\ ${ }^{2}$ Physics Institute, Potsdam University, Potsdam, Germany \\ ${ }^{3}$ Climate and Environmental Physics, Physics Institute, University of Bern, Bern, Switzerland \\ ${ }^{4}$ Oeschger Centre for Climate Change Research, Bern, Switzerland
}

Correspondence to: M. Mengel (mengel@pik-potsdam.de)

Received: 6 March 2012 - Published in Earth Syst. Dynam. Discuss.: 13 April 2012

Revised: 2 November 2012 - Accepted: 5 November 2012 - Published: 21 November 2012

\begin{abstract}
Direct observations, satellite measurements and paleo records reveal strong variability in the Atlantic subpolar gyre on various time scales. Here we show that variations of comparable amplitude can only be simulated in a coupled climate model in the proximity of a dynamical threshold. The threshold and the associated dynamic response is due to a positive feedback involving increased salt transport in the subpolar gyre and enhanced deep convection in its centre. A series of sensitivity experiments is performed with a coarse resolution ocean general circulation model coupled to a statistical-dynamical atmosphere model which in itself does not produce atmospheric variability. To simulate the impact of atmospheric variability, the model system is perturbed with freshwater forcing of varying, but small amplitude and multi-decadal to centennial periodicities and observational variations in wind stress. While both freshwater and wind-stress-forcing have a small direct effect on the strength of the subpolar gyre, the magnitude of the gyre's response is strongly increased in the vicinity of the threshold. Our results indicate that baroclinic self-amplification in the North Atlantic ocean can play an important role in presently observed SPG variability and thereby North Atlantic climate variability on multi-decadal scales.
\end{abstract}

\section{Introduction}

Most northern deep water formation occurs in the Nordic Seas in combination with strong overflows over the Greenland-Scotland ridge (GSR) and associated entrainment of surrounding water masses (Hansen et al., 2004). This deep water formation is a crucial part of the Atlantic meridional overturning circulation (AMOC), an important element of the global climate system (Rahmstorf, 2002; Kuhlbrodt et al., 2007). Simulations with a high resolution ocean model suggest that the Atlantic inflow into the Nordic Seas is modulated significantly by the strength of the subpolar gyre (SPG) south of the GSR (Hátún et al., 2005). Surface wind stress has a strong influence on the strength and variability of the SPG and the gyre strength has been linked to the northern hemisphere main mode of wind stress variability (Hurrell, 1995), the North Atlantic Oscillation (NAO) (Curry et al., 1998; Böning et al., 2006) and the Atlantic Multidecadal Oscillation (AMO) (Häkkinen et al., 2011a,b). However, part of the gyre circulation is controlled by baroclinic adjustments and thereby the density structure in the region (Greatbatch et al., 1991; Penduff et al., 2000; Eden and Willebrand, 2001).

Current diverging trends of NAO and SPG transport suggest that the classical picture of an NAO driven gyre is incomplete. Häkkinen et al. (2011a,b) argue that the frequency of atmospheric blocking and associated SLP anomalies in the eastern North Atlantic more closely resemble the variations in the SPG. A decoupling due to baroclinic effects is discussed by Hátún et al. (2009); Lohmann et al. (2009b). Direct measurements reveal a strong freshening of the region during the last four decades of the 20th century (Reverdin, 2010; Yashayaev, 2007; Häkkinen and Rhines, 2009; Curry and Mauritzen, 2005; Dickson et al., 2002; Blindheim et al., 2000) with a reversal towards higher salinities in the Eastern North Atlantic after 2001 (Holliday et al., 2008). Satellite 
observation of sea surface elevation suggest a rapid decline in SPG strength between 1992 and 2003 (Häkkinen and Rhines, 2004).

Observations, higher-resolution models and fully coupled climate models with atmospheric variability exhibit strong variations of the SPG circulation strength. Inter-annual variability can reach up to $25 \%$ of the long-term mean and variability on multi-decadal time-scales can be even stronger (Treguier et al., 2005; Hátún et al., 2005; Häkkinen and Rhines, 2009; Böning et al., 2006). However, due to their complexity the dynamical cause of the variability is often difficult to identify in these models.

In order to understand the SPG's past role in climate variability (Born and Levermann, 2010; Thornalley et al., 2009) and to project its future evolution, the gap between simulations on short time scales with high spatial resolution and those on long time scales and lower resolution needs to be overcome. The coarse-resolution climate model CLIMBER$3 \alpha$, which we apply in this study, exhibits a threshold behaviour of the Atlantic SPG with respect to surface freshwater forcing (Fig. 1) that has been related to baroclinic feedbacks in the region (Levermann and Born, 2007; Born and Mignot, 2011). Similar abrupt changes in Labrador Sea convection and the SPG have been observed in a number of models of varying complexity (LeGrande and Schmidt, 2008; Wu and Wood, 2008; Jongma et al., 2007; Weijer, 2002; Born et al., 2011) as well as sea surface temperature and sea ice reconstructions over the last $140 \mathrm{yr}$ (Dima and Lohmann, 2011). The SPG dynamics of four comprehensive coupled climate models of the CMIP3 intercomparison project are dominated by the baroclinic feedback mechanism (Born et al., 2013). The cessation of Labrador Sea convection and a subsequent weakening of the SPG is a prominent feature in 21 st century global warming simulations with atmosphere-ocean general circulation models (AOGCMS) (Yin et al., 2010; Landerer et al., 2007).

The appreciation of the SPG non-linear and feedback driven dynamics has proven useful for the understanding of historic climate events. The baroclinic response of the SPG to surface wind-stress forcing can depend on the existence of the GSR overflows and lead to two dynamically distinct regimes of the SPG in glacial and interglacial climate (Montoya et al., 2011). Paleoclimatic time series in the North Atlantic suggest that a transition of the SPG from a predominantly weak to a strong state has occurred during the so-called $8.2 \mathrm{ka}$ event at the beginning of the present interglacial (Born and Levermann, 2010) when a meltwater outburst from North American proglacial lakes weakened the Atlantic overturning circulation and led to widespread cooling over Europe. Furthermore, the SPG likely delayed the last glaciation over Scandinavia by controlling the Atlantic inflow into the Nordic Seas (Born et al., 2010, 2011).

After a brief description of the model and the experiments, we present the threshold behaviour for the SPG under stationary preindustrial boundary conditions exhibiting

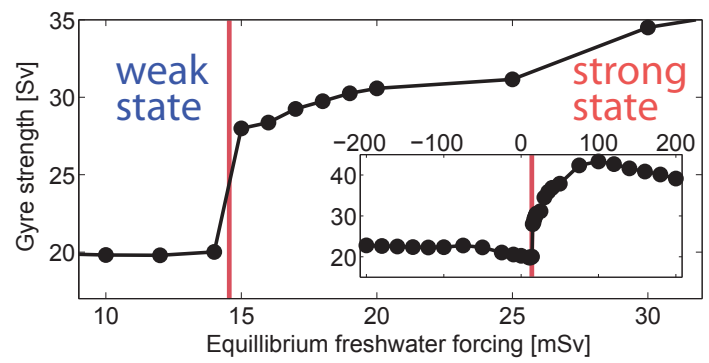

Fig. 1. Equilibrium threshold behaviour of Atlantic SPG volume transport in response to constant surface freshwater flux. The SPG exhibits a threshold behaviour at $15 \mathrm{mSv}$ freshwater forcing strength where it intensifies by more than $40 \%$. The inlay shows its response in the entire forcing interval of $\pm 200 \mathrm{mSv}$.

two distinct regimes. We then outline the feedback mechanism that potentially leads to the threshold behaviour through self-amplification in our model. We propose that this selfamplification plays a crucial role in multi-decadal gyre variability, as illustrated by the SPG response to time-dependent variations in surface freshwater flux and wind-stress as a function of the ocean state's distance from the threshold.

\section{Model and experiments}

The coupled climate model CLIMBER- $3 \alpha$ applied in this study comprises interactive atmosphere, sea ice and ocean components (Montoya et al., 2005). The oceanic general circulation model is based on the GFDL MOM-3 code (Pacanowski and Griffies, 1999), with 24 variably spaced vertical levels, a coarse horizontal resolution of $3.75^{\circ}$, a background vertical diffusivity of $\kappa_{h}=0.3 \times 10^{-4} \mathrm{~m}^{2} \mathrm{~s}^{-1}$ and an eddy-induced tracer advection with a thickness diffusion coefficient of $\kappa_{g m}=250 \mathrm{~m}^{2} \mathrm{~s}^{-1}$. If not denoted differently, wind stress is prescribed to climatology (Trenberth et al., 1989). We apply an improved version of the model used in Levermann and Born (2007) that exhibits a more realistic strength of the meridional overturning circulation.

The gyre circulation does not extend to the Labrador Sea due to the coarseness of our model. This leads to too fresh surface conditions in this region and too saline conditions at the outflow region of the Labrador Current east and southeast of Newfoundland. The East Greenland Current is fresher and broader than observed. This leads to the eastward shift of the region of subpolar deep convection to the central Irminger basin. The area of deep convection in the Greenland Basin compares well with observations of mixed layer depth (De Boyer Montégut et al., 2004).

The statistical-dynamical atmosphere model (Petoukhov et al., 2000) does not produce internal variability. We explore this shortcoming using three sets of experiments:

1. Equilibrium simulations with constant anomalous surface freshwater forcing. We run the model to 
equilibrium (at least $1000 \mathrm{yr}$ of integration) with freshwater forcing in the interval $\pm 200 \mathrm{mSv}$ and steps of $5 \mathrm{mSv}$ and refine the steps near the threshold. The freshwater flux is applied within the Nordic Seas (63.75$78.75^{\circ} \mathrm{N}$ and $\left.11.25^{\circ} \mathrm{W}-10^{\circ} \mathrm{E}\right)$.

2. Sinusoidal freshwater forcing in addition to the constant freshwater forcing freshwater of (1). Amplitudes are varied between 5 and $30 \mathrm{mSv}\left(1 \mathrm{mSv}=10^{3} \mathrm{~m}^{3} \mathrm{~s}^{-1}\right)$ and periods are 25 to $200 \mathrm{yr}$. The freshwater forcing is applied in the same geographical region as (1).

3. Time-varying surface wind stress reanalysis forcing in addition to (1). We add surface wind stress anomalies from the National Centers for Atmospheric Prediction (NCEP) and National Center for Atmospheric Research (NCAR) reanalysis (Kalnay et al., 1996) to the climatology (Trenberth et al., 1989). Wind stress anomalies were computed as the annual mean minus the average over the full period from 1948 to 2009. In order to avoid drifts and discontinuities, the anomalies time series from 1948-2009 are continued by their timereversed time series. The resulting 122 -yr-long time series is cyclic and is used as a long-term representation of 1948-2009 variability. In order to let the simulation run into a dynamic equilibrium this forcing is repeated several times.

Note that no freshwater forcing is applied on the convection sites south of the Greenland-Scotland Ridge and thereby no direct influence on the SPG is induced. We will show here that the remote forcing, however, induces strong shifts in the SPG dynamics.

\section{SPG threshold behaviour and mechanism of transition}

In response to a constant surface freshwater forcing, we identify a threshold behaviour with two distinct regimes of circulation (Fig. 1). Within the explored forcing interval between $\pm 200 \mathrm{mSv}$ (inlay in Fig. 1) we find a sharp increase of $40 \%$ (from 20 to $28 \mathrm{~Sv}$ ) in SPG volume transport, measured as the maximum absolute value of the horizontal stream function in the gyre region, at $15 \mathrm{mSv}$ anomalous freshwater forcing. This value is well within the range of natural variability (Curry and Mauritzen, 2005) and may easily be exceeded under global warming (Dickson et al., 2007).

We find warmer and saltier conditions in the upper $1000 \mathrm{~m}$ waters at the southern GSR as the predominant early response to freshwater forcing in the Nordic Seas in our model. In contrast, the deep overflow density shows little changes. Hansen et al. (2004) argue that thermohaline forcing drives the Atlantic inflow to the Nordic Seas. The inflow balances the deep overflows and depends on the deep water production rate in the Nordic Seas. Reducing the deep water production through freshwater forcing thus leads to diminished inflow. The applied freshwater forcing is too small to alter the density in the North Atlantic significantly. Since the strength of the AMOC is largely determined by the density difference between the North and South Atlantic (Griesel and Maqueda, 2006; Schewe and Levermann, 2010), the AMOC does not change in response to the additional forcing and the overall deep water formation in the North Atlantic and Nordic Seas is approximately constant. Consequently, reduced deep water formation north of the GSR enhances downwelling south of the ridge within the SPG and more water recirculates in the subpolar basin. This is consistent with the signal of warmer and saltier waters at the southern GSR. We thus argue that the forcing signal does not trigger subpolar changes through the overflows but through its influence on the Atlantic inflow.

The strong circulation regime is characterised by a cooler SPG centre and a warmer northern rim (Fig. 2a and b). Lohmann et al. (2009a) have shown that on inter-annual to decadal time scales a strong positive NAO forcing leads to a stronger SPG and the cooling of subpolar mode waters (their Fig. 7a) through high atmospheric heat loss. The same signal is seen in the NCEP-NCAR driven simulations in Hátún et al. (2005). This does not contradict our results because the response on the longer than decadal scale is dominated by the increased transport of warm NAC waters into the subpolar mode water region (Lohmann et al., 2009a, Fig. 7b), resembling the pattern we show in Fig. 2a.

Surface salinities are higher along the path of waters advected from the North Atlantic Current (NAC) at the northern part of the gyre (Fig. 2c and d) with positive anomalies extending into the SPG centre. The density increase over the whole upper $1000 \mathrm{~m}$ in the centre (Fig. 2e and f) is, however, dominated by lower temperatures (compare to Fig. 2a and b).

The cooling, freshening and density increase at the southern part of the SPG reflects the southeastward shift of the NAC due to the intensification and associated spatial expansion of the SPG (Fig. 2h). This expansion is in line with observations and model studies (Bersch et al., 2007; Häkkinen and Rhines, 2009; Häkkinen et al., 2011a). However, the southward extension (Hátún et al., 2005; Bersch et al., 2007) associated with a south-north aligned SPG during weak state differs from the behaviour in our model. The southward shift of the NAC during strong gyre circulation may thus be model specific.

A prominent feature of the strong circulation is a southward expansion of the winter convection at the SPG centre (Fig. 2, green rectangles). The heat flux to the atmosphere increases over the northern SPG region (Fig. 2g) and ensures that the additional heat that is advected with the warmer NAC waters is released to the atmosphere in such a way that there is a net cooling in the centre of the SPG. The strong negative heat flux anomaly at the southern SPG rim (Fig. $2 \mathrm{~g}$ ) is due to a southward shift of the NAC.

The intensification of the transport is in geostrophic balance with the density changes in the gyre. Consequently, the 

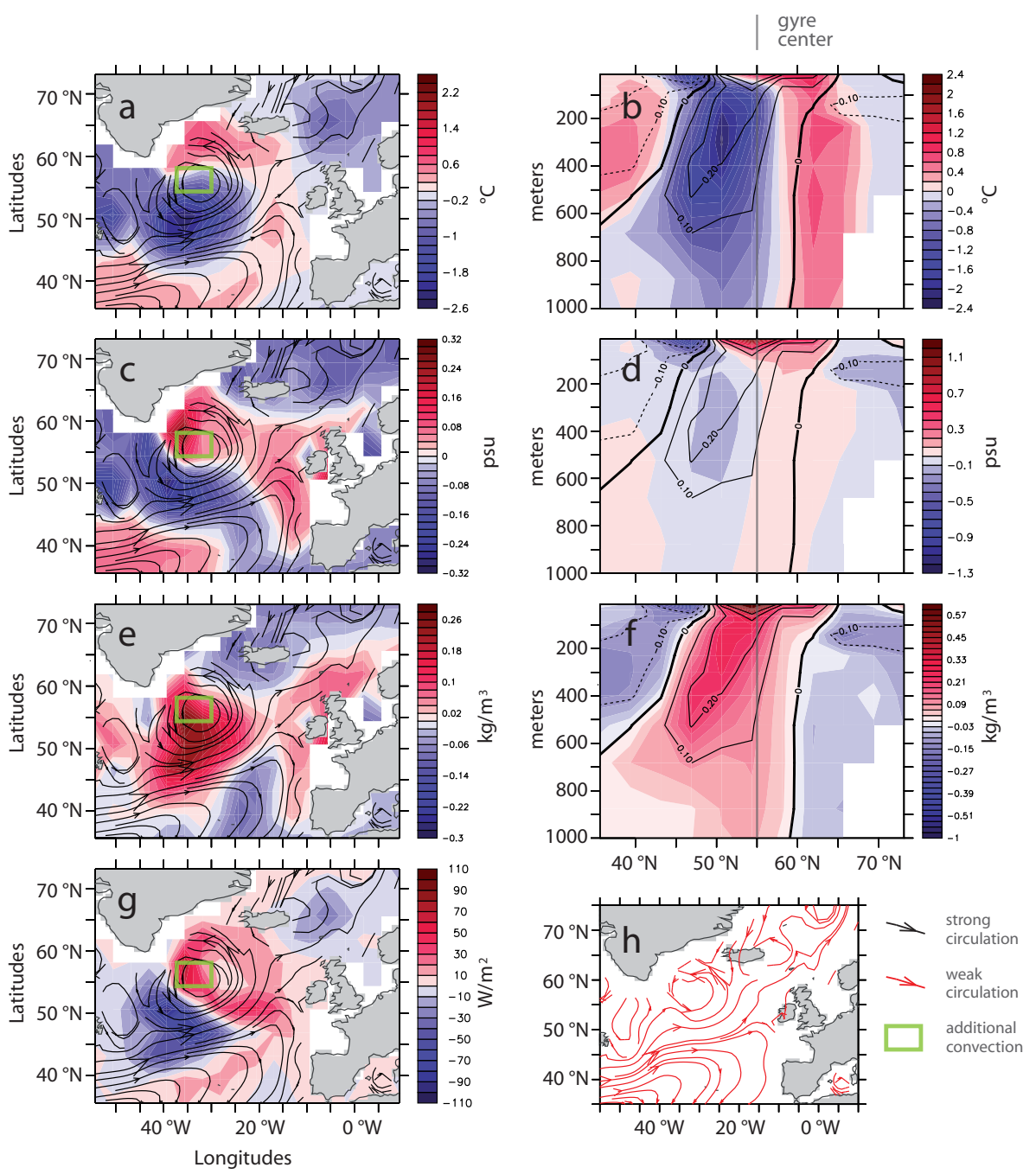

Fig. 2. Difference between the strong ( $15 \mathrm{mSv}$ forcing) and weak (control) SPG circulation. Panels (a, b) show temperature, (c, d) salinity, (e, f) density and (g) heatflux. Panels (a, c, e) show averages over the upper $1000 \mathrm{~m}$, black flowlines in panels (a, c, e, g) show upper $1000 \mathrm{~m}$ strong state velocities. Panel (h) shows weak upper $1000 \mathrm{~m}$ velocities as flowlines in red. Panels (b, d, f) show zonal averages between $37.5^{\circ}$ and $18.75^{\circ} \mathrm{W}$ with density anomalies as contours and the approximate gyre centre as a grey line.

stronger gyre is associated with an enhanced density difference between its denser centre and the relatively light outer rim of the gyre. This finding has been discussed in detail by Levermann and Born (2007). Since we find a threshold behaviour in equilibrium simulations, the non-linear transition between the weak and the strong gyre state has to be linked to positive feedbacks within the system.

Feedback mechanisms that drive SPG dynamics through the density difference between the centre and rim have been identified in earlier studies. Levermann and Born (2007) state that enhanced salinity import from the tropics to the gyre centre when gyre circulation is strong drives further densification of the centre. This is consistent with Hátún et al. (2005) who find increased salt-inflow in the Nordic Seas for periods of a weak SPG in a high-resolution model. The anomalous advection of salt and subsequent stronger convection in the Irminger basin has been identified as a possible source of multi-decadal AMOC fluctuations (Msadek and Frankignoul, 2009). Born et al. (2013) identified four CMIP3 AOGCMs where this salinity-advection feedback drives SPG dynamics through enhanced convection.

Consistent with these studies, in our model a stronger SPG imports more saline waters from the NAC that are transported to the SPG centre (Fig. 2c and d). That enables stronger winter convection and leads to a colder SPG centre (Fig. 2a and $b$ ). The increased density contrasts between centre and exterior gyre causes a stronger gyre circulation that captures more saline waters. This feedback loop is illustrated in Fig. 3.

Even though our coarse resolution model fails to represent North Atlantic ocean-atmosphere dynamics in their full complexity, the mechanism reported here is consistent with the relation between the cessation of subpolar deep convection 


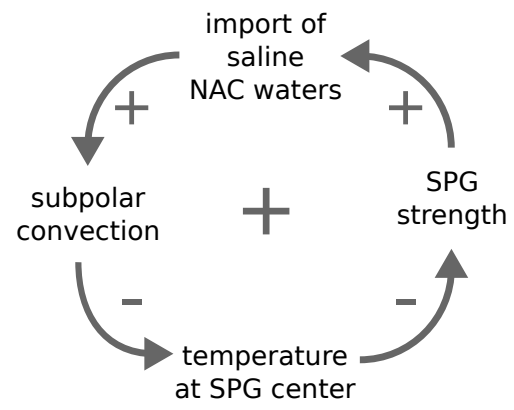

Fig. 3. The feedback loop that leads to the self-amplification of the SPG transport as described in the text. The stronger SPG imports more warm and saline water from the North Atlantic Current; thus increasing the surface salinity in the subpolar region, which fosters winter convection and thereby leads to lower temperatures at the SPG centre. Thus increasing the centre-rim density contrast and thus geostrophic SPG transport.

in the mid-1990s and a slowing down and westward contraction (Bersch et al., 2007; Häkkinen and Rhines, 2004, 2009; Häkkinen et al., 2011a) of the SPG which is speculated to be induced by internal dynamics (Lohmann et al., 2009b).

We diagnose the AMOC to be $6.5 \%$ weaker in the strong circulation regime than in the control simulation of our model. The AMOC weakening during the increase of SPG transport is consistent with the observational data and model results (Zhang, 2008; Manabe and Stouffer, 1999), also on high resolution eddy-permitting scale (Zhang et al., 2011).

\section{Role of threshold for SPG variability}

In order to investigate the role of the threshold behaviour for SPG variability, we introduced temporal variations in surface freshwater and wind stress forcing (Fig. 4). In the standard simulation, i.e. without a constant off-set in freshwater forcing and thereby far away from the threshold, the application of the observed wind stress anomalies results in relatively weak SPG variability of less than $2 \mathrm{~Sv}$. Similarly low variability is obtained for sinusoidal surface freshwater flux variations with $20 \mathrm{mSv}$ amplitude and a period of $100 \mathrm{yr}$.

The SPG response drastically increases when the system is brought closer to the threshold by application of a constant freshwater flux off-set. In this case both forcings induce a high SPG variability of $10 \mathrm{~Sv}$ for wind-stress and $15 \mathrm{~Sv}$ for sinusoidal freshwater forcing, respectively. Similar values were obtained from satellite sea surface height observations (Häkkinen and Rhines, 2004, 2009) and model results (Böning et al., 2006) yielding $10 \mathrm{~Sv}$ transport variability or $25 \%$ of the long-term average.

Spatial patterns of variability for temperature, salinity and density mimic the anomaly patterns we discussed in Sect. 3 . Thus, the increase of variability originates from the feedback driven dynamical regime in our model. The high correlation

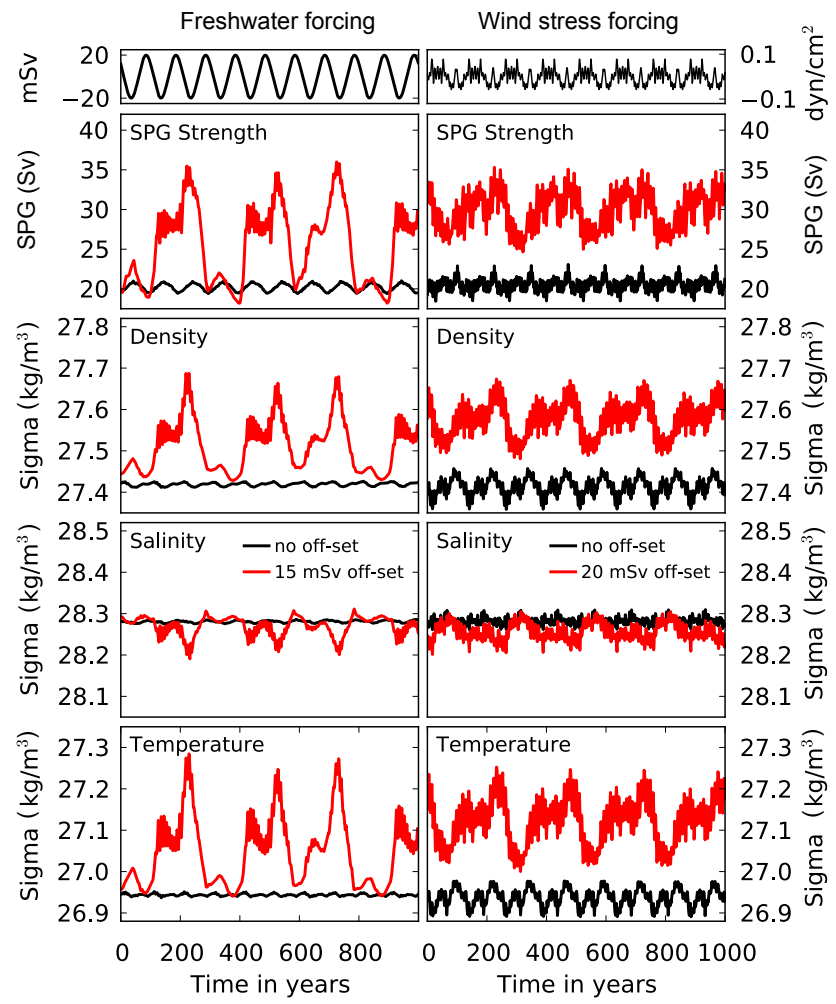

Fig. 4. Time series of SPG strength showing enhanced variability near the dynamical threshold due to the baroclinic feedback. Left panels show the response to sinusoidal freshwater forcing with $20 \mathrm{mSv}$ amplitude and a period of $100 \mathrm{yr}$, right panels to NCEPNCAR surface wind stress anomaly. Red curves are with constant freshwater off-set of $20 \mathrm{mSv}$ and black curves are without off-set. Narrow upper two panels show the time-varying forcing. The large panels show from top to bottom SPG strength, density variations, density variations due to salinity alone and density variations due to temperature alone. Averages are taken between $37.5^{\circ} \mathrm{W}-18.75^{\circ} \mathrm{W}$ and $45^{\circ} \mathrm{N}-60^{\circ} \mathrm{N}$ in the upper $1000 \mathrm{~m}$. In both the cases of freshwater and wind forcing the SPG variability is significantly weaker than observed when the system is far from the threshold (black curves). In the vicinity of the dynamical threshold of Fig. 1, the SPG variability is drastically increased. The main density signal is produced by temperature variations. Major salinity changes are restricted to the surface layers, but play a key role in the process of self-amplification (see Fig. 3).

of centre temperature, centre density and SPG strength in Fig. 4 supports this finding. Salinity plays an important role in modulating convection but does not drive density changes directly, it is anticorrelated with density in the upper $1000 \mathrm{~m}$ average.

The robustness of the variability increase is detailed in Fig. 5 where the SPG mean and standard deviation are plotted over the respective freshwater flux off-set. Different colours correspond to different forcing amplitudes of the sinusoidal freshwater flux. The qualitative behaviour is best seen for a forcing amplitude of $100 \mathrm{yr}$ : SPG variability shows an abrupt 

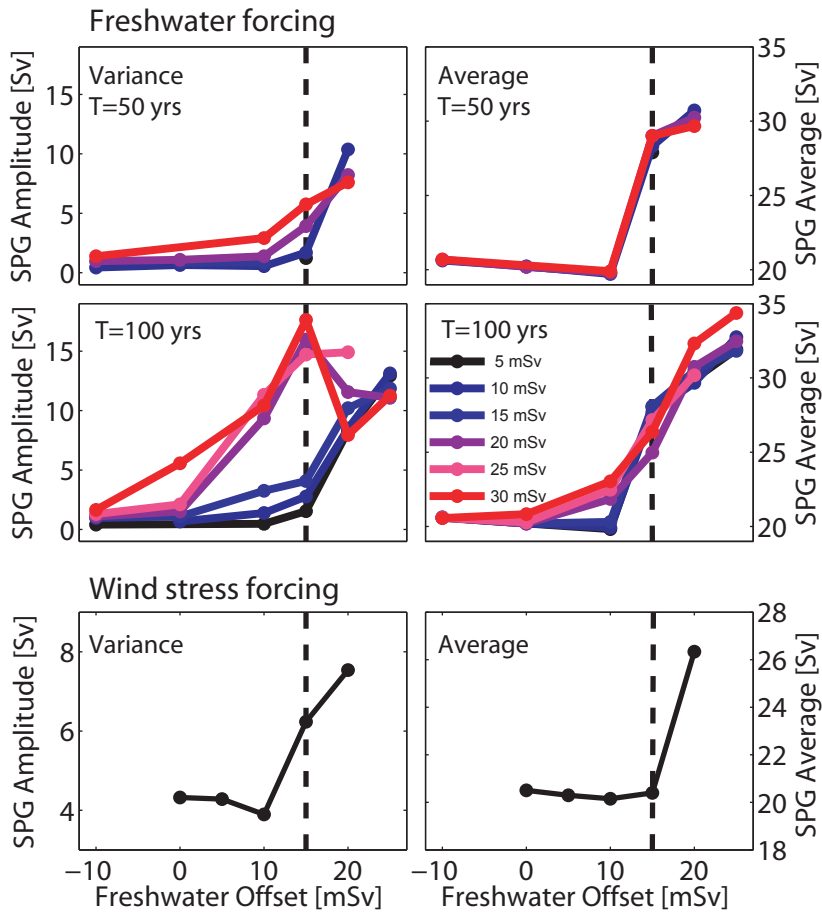

Fig. 5. Upper and middle panels: mean SPG strength and its variability for different constant off-set in surface freshwater flux. Different lines correspond to the forcing amplitudes as denoted in the legend. Lower panels: Wind induced variability of the SPG for different constant freshwater off-sets. The dashed vertical line marks the position of the equilibrium threshold at $15 \mathrm{mSv}$ (compare to Fig. 1). The amplitude of SPG variations increases when approaching the threshold for both time-varying freshwater and wind stress forcing. This is best seen for the $100 \mathrm{yr}$ period freshwater forcing, but still present on the shorter time scales $(50 \mathrm{yr}$ period and wind stress forcing). Even close to the threshold the system's response to NCEP wind stress variability is significantly smaller than its response to centennial scale freshwater variations. The lower panels have a different $y$-scale.

increase at an off-set similar to the threshold for constant freshwater forcing of $15 \mathrm{mSv}$. The variability decreases when we move away from the threshold towards higher offsets. The increase of mean and variability are not tightly linked. Variability is high for runs near the threshold because the SPG meanders between the two equilibrium states. Mean strength monotonically increases with higher offsets, analogous to the equilibrium simulations. This particular feature illustrates the dynamic core of the variability. Though the transition of the time-dependent behaviour reflects the equilibrium threshold of Fig. 1, it is not equivalent to the equilibrium response but reflects a dynamical behaviour as expressed in the variance. The dynamical transition occurs over a large interval of forcing amplitudes and is largely independent of this forcing amplitude.

The model's response to external forcing increases with the period of the freshwater forcing from $8 \mathrm{~Sv}$ ( $50 \mathrm{yr}$ period)

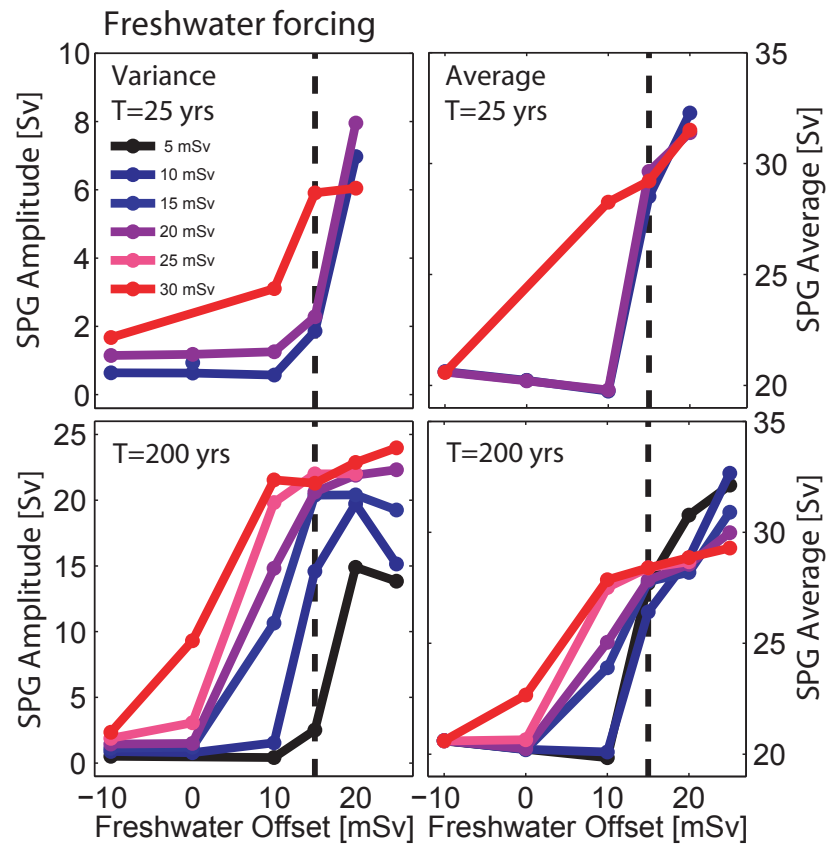

Fig. 6. Mean SPG strength and its variability for varying perturbation amplitude corresponding to Fig. 5, but for periods of 25 and $200 \mathrm{yr}$. Different lines correspond to different forcing amplitudes as denoted in the legend.

to more than $23 \mathrm{~Sv}$ (200 yr period) forcing (Figs. 5 and 6). Forcings with periods shorter than $25 \mathrm{yr}$ do not yield the same variability increase. We thus argue that the signal transport on advective, inter-decadal time scales dominates the dynamics in this study.

For reanalysis surface wind stress forcing (Fig. 5, lower panels) we observe a similar behaviour. SPG variability is relatively constant at a low level as long as the SPG is too far from the threshold. At the threshold of $15 \mathrm{mSv}$ of constant freshwater off-set the amplitude of the time-varying response increases and stays strong beyond the threshold.

The SPG variability induces an atmospheric response pattern that resembles the large scale air pressure pattern of a positive NAO phase (Fig. 7). We thus speculate that the mechanism of oceanic variability identified in this study may reverberate in the large scale atmospheric variability patterns of the Northern Hemisphere. A similar footprint has been detected in atmosphere general circulation model simulations forced with observed sea surface temperature anomalies (Rodwell et al., 1999) and experiments with a fully coupled AOGCM (Yoshimori et al., 2010). 

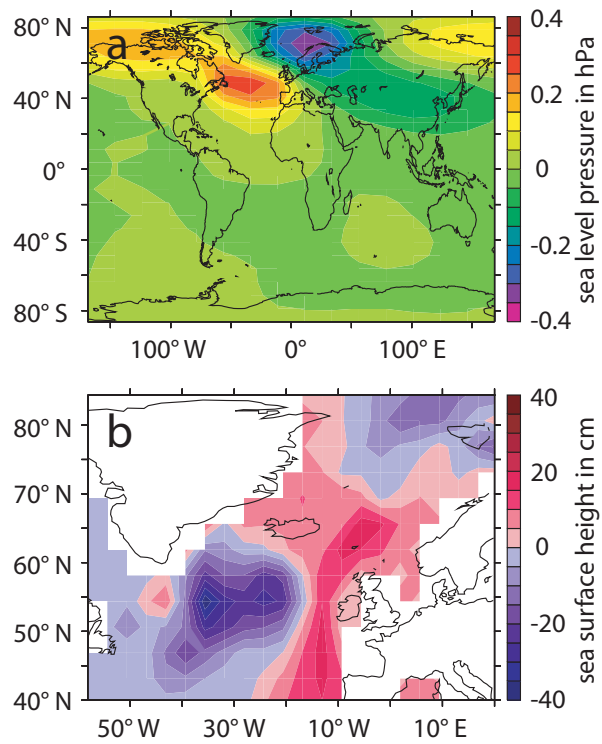

Fig. 7. Sea level pressure (a) and sea surface height (b) difference of strong minus weak SPG state with $100 \mathrm{yr}$ period sinusoidal freshwater forcing of $20 \mathrm{mSv}$ amplitude.

\section{Conclusion and discussion}

Here we present simulations with a coarse-resolution climate model to better understand the mechanisms of SPG variability. In equilibrium, the SPG exhibits a threshold behaviour with respect to surface freshwater flux which results from a positive baroclinic feedback within the subpolar region. It is important to note that the freshwater is not applied on the SPG but north of the Greenland-Scotland Ridge. The SPG response is thereby induced by circulation changes through the baroclinic feedback. This non-linear behaviour enhances SPG variability drastically for variations in surface freshwater forcing with a magnitude comparable to observed changes in precipitation in the region.

Wind-stress forcing from reanalysis data only produces gyre transport variability similar to observations if the system is brought close to the threshold. The observed high variability of SPG transport (Häkkinen et al., 2011b) may thus indicate a near-threshold gyre circulation. A near-threshold gyre circulation might collapse into a permanent weak SPG circulation as found in model simulations under global warming scenarios (Yin et al., 2009).

The presented mechanism of variability provides an alternative approach to these derived from fully coupled simulations to explain North Atlantic multidecadal variability. See Grossmann and Klotzbach (2009) for a review. The export of sea ice to the subpolar North Atlantic has been found to induce $A M O C$ variability through its influence on subpolar convection, see for example Holland et al. (2001). Oka et al. (2012) suggest a thermal threshold originating from the interplay of Nordic Seas sea ice cover, convection and the AMOC strength. Timmermann et al. (1998) identified a delayed negative feedback between North Atlantic surface water temperatures, the North Atlantic Oscillation and convection to foster variability through a coupled air-sea mode.

While it is clear that our results are not directly applicable to presently observed variability on interannual time scales, they suggest a potential role of the associated baroclinic feedback on multi-decadal time scales. In fact, the abrupt weakening of the SPG during the 1990s has been associated with the decay of the density difference between inner and exterior gyre through thermohaline forcing (Häkkinen and Rhines, 2004).

In our simulations the SPG does not respond to forcing shorter than $25 \mathrm{yr}$, pronounced variability is found for periods of $50 \mathrm{yr}$ and longer. The signal transport on advective, inter-decadal time scales thus dominates. Time delayed advective adjustment has been proposed to drive NA variability (Lee and Wang, 2010) and Zhang et al. (2011) showed that the baroclinic adjustment on advective time scales can dominate also in high resolution eddy-permitting models. The increasing amplitude with the length of the forcing period further supports the dominance of long adjustment time scales. A general problem of coarse resolution models is the dilution of temperature and salinity signals due to the large grid boxes. We thus hypothesize that the time scales in our model might be larger than they would be at higher resolution where the adjustment through planetary waves may come into play. In that case strong variability of a shorter period than $50 \mathrm{yr}$ might be possible and mechanisms of variability on a subdecadal scale may come into play (Lee and Wang, 2010).

The average net surface freshwater flux over the Nordic Seas in our control simulation is $47.4 \mathrm{mSv}$, comparing well to the $54 \mathrm{mSv}$ estimated by Dickson et al. (2007). Still, we cannot rule out that the $1000 \mathrm{yr}$ average state of the ocean has deficiencies and the distance to the SPG threshold exceeds the value presented here.

Model studies and observations found a threshold behaviour for the subpolar convection and the SPG circulation (Legrande et al., 2006; Wu and Wood, 2008; Thornalley et al., 2009; Born et al., 2011). This indicates the robustness of our results though artefacts due to the low resolution or deficiencies in the density structure cannot be ruled out. Analyses of higher resolution models with and without atmospheric variability are necessary to confirm our results.

Acknowledgements. This research was supported by the German Environmental Foundation (DBU) and the German National Academic Foundation. A. B. is supported by the European Commission under the Marie Curie Intra-European Fellowship ECLIPS (PIEF-GA-2011-300544) and the "National Centre for Excellence in Research: Climate" of the Swiss National Science Foundation.

Edited by: K. Keller 


\section{References}

Bersch, M., Yashayaev, I., and Koltermann, K. P.: Recent changes of the thermohaline circulation in the subpolar North Atlantic, Ocean Dynam., 57, 223-235, 2007.

Blindheim, J., Borovkov, V., Hansen, B., Malmberg, S.-A., Turrell, W. R., and Osterhus, S.: Upper layer cooling and freshening in the Norwegian Sea in relation to atmospheric forcing, Deep-Sea Res. Pt. I, 47, 655-680, 2000.

Böning, C. W., Scheinert, M., Dengg, J., Biastoch, A., and Funk, A.: Decadal variability of subpolar gyre transport and its reverberation in the North Atlantic overturning, Geophys. Res. Lett., 33, L21S01, doi:10.1029/2006GL026906, 2006.

Born, A. and Levermann, A.: The $8 \mathrm{k}$ event: abrupt transition of the subpolar gyre towards a modern North Atlantic circulation, Geochem. Geophy. Geosy., 11, Q06011, doi:10.1029/2009GC003024, 2010.

Born, A. and Mignot, J.: Dynamics of decadal variability in the Atlantic subpolar gyre: a stochastically forced oscillator, Climate Dynamics, pp. 591-+, 2011.

Born, A., Nisancioglu, K., and Braconnot, P.: Sea ice induced changes in ocean circulation during the Eemian, Clim. Dynam., 35, 1361-1371, 2010.

Born, A., Nisancioglu, K., and Risebrobakken, B.: Late Eemian warming in the Nordic Seas as seen in proxy data and climate models, Paleoceanography, 26, PA2207, doi:10.1029/2010PA002027, 2011.

Born, A., Stocker, T. F., Levermann, A., and Raible, C. C.: Is the Atlantic subpolar gyre bistable in comprehensive coupled climate models?, Clim. Dynam., 39, 1-15, doi:10.1007/s00382012-1525-7, 2013.

Curry, R. G. and Mauritzen, C.: Dilution of the Northern North Atlantic Ocean in Recent Decades, Science, 308, 1772-1774, 2005.

Curry, R. G., McCartney, M. S., and Joyce, T. M.: Oceanic transport of subpolar climate signals to mid-depth subtropical waters, Nature, 391, 575-577, 1998.

De Boyer Montégut, C., Madec, G., Fischer, A. S., Lazar, A., and Iudicone, D.: Mixed layer depth over the global ocean: An examination of profile data and a profile-based climatology, J. Geophys. Res., 109, 1-20, 2004.

Dickson, B., Yashayaev, I., Meincke, J., Turrell, B., Dye, S., and Holfort, J. T.: Rapid freshening of the deep North Altantic Ocean over the past four decades, Nature, 416, 832-837, 2002.

Dickson, R., Rudels, B., Dye, S., Karcher, M., Meincke, J., and Yashayaev, I.: Current estimates of freshwater flux through Arctic and subarctic seas, Prog. Oceanogr., 73, 210-230, doi:10.1016/j.pocean.2006.12.003, 2007.

Dima, M. and Lohmann, G.: Hysteresis Behavior of the Atlantic Ocean Circulation identified in Observational Data, J. Climate, 24, 397-403, 2011.

Eden, C. and Willebrand, J.: Mechanism of Interannual to Decadal Variability of the North Atlantic Circulation, J. Climate, 14, 2266-2280, 2001.

Greatbatch, R. J., Fanning, A. F., Goulding, A. D., and Levitus, S.: A diagnosis of interpentadal circulation changes in the North Atlantic, J. Geophys. Res., 96, 22009-22023, 1991.

Griesel, A. and Maqueda, M. A. M.: The relation of meridional pressure gradients to North Atlantic deep water volume transport in an ocean general circulation model, Clim. Dynam., 26, 781-799, doi:10.1007/s00382-006-0122-z, 2006
Grossmann, I. and Klotzbach, P. J.: A review of North Atlantic modes of natural variability and their driving mechanisms, J. Geophys. Res., 114, 1-14, doi:10.1029/2009JD012728, 2009.

Häkkinen, S. and Rhines, P. B.: Decline of Subpolar North Atlantic Circulation During the 1990s, Science, 304, 555-559, 2004.

Häkkinen, S. and Rhines, P. B.: Shifting surface currents in the northern North Atlantic Ocean, J. Geophys. Res., 114, C04005, doi:10.1029/2008JC004883, 2009.

Häkkinen, S., Rhines, P., and Worthen, D.: Warm and saline events embedded in the meridional circulation of the northern North Atlantic, Journal of Geophysical Research (Oceans), 116, 3006, doi:10.1029/2010JC006275, 2011a.

Häkkinen, S., Rhines, P., and Worthen, D.: Atmospheric Blocking and Atlantic Multidecadal Ocean Variability, Science, 334, 655659, doi:10.1126/science.1205683, 2011b.

Hansen, B., Østerhus, S., Quadfasel, D., and Turrell, W.: Already the Day After Tomorrow ?, Science, 305, 953-954, 2004.

Hátún, H., Sandø, A. B., Drange, H., Hansen, B., and Valdimarsson, H.: Influence of the Atlantic Subpolar Gyre on the Thermohaline Circulation, Science, 309, 1841-1844, 2005.

Hátún, H., Payne, M., Beaugrand, G., Reid, P., Sandø, A., Drange, H., Hansen, B., Jacobsen, J., and Bloch, D.: Large biogeographical shifts in the north-eastern Atlantic Ocean: From the subpolar gyre, via plankton, to blue whiting and pilot whales, Prog. Oceanogr., 80, 149-162, 2009.

Holland, M. M., Bitz, C. M., Eby, M., and Weaver, A. J.: The Role of Ice-Ocean Interactions in the Variability of the North Atlantic Thermohaline Circulation, J. Climate, 14, 656-675, doi:10.1175/1520-0442(2001)014<0656:TROIOI > 2.0.CO;2, 2001.

Holliday, N., Hughes, S., Bacon, S., Beszczynska-Möller, A., Hansen, B., Lavín, A., Loeng, H., Mork, K., Østerhus, S., Sherwin, T., and Walczowski, W.: Reversal of the 1960s to 1990s freshening trend in the northeast North Atlantic and Nordic Seas, Geophys. Res. Lett., 35, L03614, doi:10.1029/2007GL032675, 2008.

Hurrell, J. W.: Decadal trends in North Atlantic Oscillation: Regional Temperatures and Precipitation, Science, 269, 676-679, doi:10.1126/science.269.5224.676, 1995.

Jongma, J., Prange, M., Renssen, H., and Schulz, M.: Amplification of Holocene multicentennial climate forcing by mode transitions in North Atlantic overturning circulation, Geophys. Res. Lett., 34, L15706, doi:10.1029/2007GL030642, 2007.

Kalnay, E., Kanamitsu, M., Kistler, R., Collins, W., Deaven, D., Gandin, L., Iredell, M., Saha, S., White, G., Woollen, J., Zhu, Y., Chelliah, M., Ebisuzaki, W., Higgins, W., Janowiak, J., Mo, K. C., Ropelewski, C., Wang, J., Leetmaa, A., Reynolds, R., Jenne, R., and Joseph, D.: The NCEP/NCAR 40-Year Reanalysis Project, B. Am. Meteorol. Soc., 77, 437-471, 1996.

Kuhlbrodt, T., Griesel, A., Montoya, M., Levermann, A., Hofmann, M., and Rahmstorf, S.: On the driving processes of the Atlantic meridional overturning circulation, Rev. Geophys., 45, RG2001, doi:10.1029/2004RG000166, 2007.

Landerer, F. W., Jungclaus, J. H., and Marotzke, J.: Regional Dynamic and Steric Sea Level Change in Response to the IPCCA1B Scenario, J. Phys. Oceanogr., 37, 296-312, 2007.

Lee, S.-K. and Wang, C.: Delayed Advective Oscillation of the Atlantic Thermohaline Circulation, J. Climate, 23, 1254-1261, doi:10.1175/2009JCLI3339.1, 2010. 
LeGrande, A. and Schmidt, G.: Ensemble, water isotopeenabled, coupled general circulation modeling insights into the $8.2 \mathrm{ka}$ event, Paleoceanography, 23, PA3207, doi:10.1029/2007GL031732, 2008.

Legrande, A., Schmidt, G., Shindell, D., Field, C., Miller, R., Koch, D., Faluvegi, G., and Hoffmann, G.: Consistent simulations of multiple proxy responses to an abrupt climate change event, $\mathrm{P}$. Natl. Acad. Sci., 103, 837-842, 2006.

Levermann, A. and Born, A.: Bistability of the subpolar gyre in a coarse resolution climate model, Geophys. Res. Lett., 34, L24605, doi:10.1029/2009GL039166, 2007.

Lohmann, K., Drange, H., and Bentsen, M.: Response of the North Atlantic subpolar gyre to persistent North Atlantic oscillation like forcing, Clim. Dynam., 32, 273-285, doi:10.1007/s00382008-0467-6, 2009a.

Lohmann, K., Drange, H., and Bentsen, M.: A possible mechanism for the strong weakening of the North Atlantic subpolar gyre in the mid-1990s, 36, L15602, doi:10.1029/2007GL031732, 2009b.

Manabe, S. and Stouffer, R.: The rôle of thermohaline circulation in climate, Tellus A, 51, 91-109, 1999.

Montoya, M., Griesel, A., Levermann, A., Mignot, J., Hofmann, M., Ganopolski, A., and Rahmstorf, S.: The Earth System Model of Intermediate Complexity CLIMBER-3 $\alpha$, Part I: description and performance for present day conditions, Clim. Dynam., 25, 237263, 2005.

Montoya, M., Born, A., and Levermann, A.: Reversed North Atlantic gyre dynamics in present and glacial climates, Clim. Dynam., 36, 1107-1118, doi:10.1007/s00382-009-0729-y, 2011.

Msadek, R. and Frankignoul, C.: Atlantic multidecadal oceanic variability and its influence on the atmosphere in a climate model, Clim. Dynam., 33, 45-62, doi:10.1007/s00382-0080452-0, 2009.

Oka, A., Hasumi, H., and Abe-Ouchi, A.: The thermal threshold of the Atlantic meridional overturning circulation and its control by wind stress forcing during glacial climate, Geophys. Res. Lett., 39, 1-6, doi:10.1029/2012GL051421, 2012.

Pacanowski, R. C. and Griffies, S. M.: The MOM-3 manual, Tech. Rep. 4, NOAA/Geophyical Fluid Dynamics Laboratory, Princeton, NJ, USA, 1999.

Penduff, T., Barnier, B., and de Verdière, A. C.: Self-adapting open boundaries for a sigma coordinate model of the eastern North Atlantic, J. Geophys. Res., 105, 211-279, 2000.

Petoukhov, V., Ganopolski, A., Brovkin, V., Claussen, M., Eliseev, A., Kubatzki, C., and Rahmstorf, S.: CLIMBER-2: a climate system model of intermediate complexity, Part I: model description and performance for present climate, Clim. Dynam., 16, 1-19, 2000.

Rahmstorf, S.: Ocean circulation and climate during the past 120,000 years, Nature, 419, 207-214, 2002.
Reverdin, G.: North atlantic subpolar gyre surface variability (1895-2009), J. Climate, 23, 4571-4584, doi:0.1175/2010JCLI3493.1, 2010.

Rodwell, M., Rowell, D., and Folland, C.: Oceanic forcing of the wintertime North Atlantic Oscillation and European climate, Nature, 398, 320-323, doi:10.1038/18648, 1999.

Schewe, J. and Levermann, A.: The role of meridional density differences for a wind-driven overturning circulation, Clim. Dynam., 34, 547-556, 2010.

Thornalley, D., Elderfield, H., and McCave, I.: Holocene oscillations in temperature and salinity of the surface subpolar North Atlantic, Nature, 457, 711-714, doi:10.1038/nature07717, 2009.

Timmermann, A., Latif, M., Voss, R., and Groetzner, A.: Northern hemispheric interdecadal variability: a coupled air-sea mode, J. Climate, 11, 1906-1931, 1998.

Treguier, A. M., Theetten, S., Chassignet, E. P., Penduff, T., Smith, R., Talley, L., Beismann, J. O., and Böning, C.: The North Atlantic Subpolar Gyre in Four High-Resolution Models, J. Climate, 35, 757-774, 2005.

Trenberth, K., Olson, J., and Large, W.: A Global Ocean Wind Stress Climatology based on ECMWF Analyses, Tech. Rep. NCAR/TN-338+STR, National Center for Atmospheric Research, Boulder, Colorado, USA, 1989.

Weijer, W.: Response of the Atlantic overturning circulation to South Atlantic sources of buoyancy, Global Planet. Change, 34, 293-311, 2002.

Wu, P. and Wood, R.: Convection induced long term freshening of the subpolar North Atlantic Ocean, Clim. Dynam., 31, 941-956, 2008.

Yashayaev, I.: Hydrographic changes in the Labrador Sea, 19602005, Prog. Oceanogr., 73, 242-276, 2007.

Yin, J., Schlesinger, M. E., and Stouffer, R. J.: Model projections of rapid sea-level rise on the northeast coast of the United States, Nat. Geosci., 2, 262-266, 2009.

Yin, J., Griffies, S., and Stouffer, R.: Spatial Variability of Sea Level Rise in Twenty-First Century Projections, J. Climate, 23, 45854607, 2010.

Yoshimori, M., Raible, C., Stocker, T., and Renold, M.: Simulated decadal oscillations of the Atlantic meridional overturning circulation in a cold climate state, Clim. Dynam., 34, 101-121, 2010.

Zhang, R.: Coherent surface-subsurface fingerprint of the Atlantic meridional overturning circulation, Geophys. Res. Lett., 35, L20705, doi:10.1029/2008GL035463, 2008.

Zhang, R., Delworth, T. L., Rosati, A., Anderson, W. G., Dixon, K. W., Lee, H.-C., and Zeng, F.: Sensitivity of the North Atlantic Ocean Circulation to an abrupt change in the Nordic Sea overflow in a high resolution global coupled climate model, J. Geophys. Res., 116, 1-14, doi:10.1029/2011JC007240, 2011. 